LUMBAR SPINE DISORDERS Current Concepts 
This page is intentionally left blank 


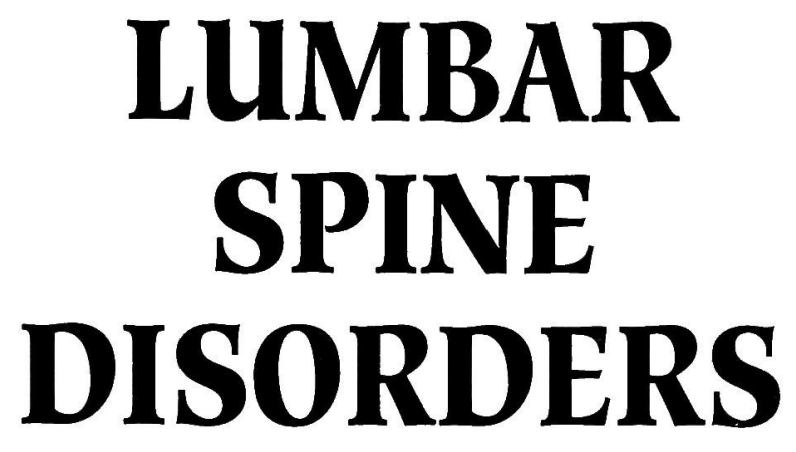

\section{Current Concepts}

\section{Editors}

\section{R. M. Aspden R. W. Porter}

Department of Orthopaedic Surgery University of Aberdeen 


\section{Published by}

World Scientific Publishing Co. Pte. Ltd.

P O Box 128, Farrer Road, Singapore 9128

USA office: Suite 1B, 1060 Main Street, River Edge, NJ 07661

UK office: 57 Shelton Street, Covent Garden, London WC2H 9HE

\section{LUMBAR SPINE DISORDERS: CURRENT CONCEPTS}

Copyright (C) 1995 by World Scientific Publishing Co. Pte. Ltd.

All rights reserved. This book, or parts thereof, may not be reproduced in any form or by any means, electronic or mechanical, including photocopying, recording or any information storage and retrieval system now known or to be invented, without written permission from the Publisher.

For photocopying of material in this volume, please pay a copying fee through the Copyright Clearance Center, Inc., 27 Congress Street, Salem, MA 01970, USA.

ISBN: $981-02-2175-4$

Printed in Singapore. 
Great are the works of the Lord, Studied by all who have pleasure in them.

Psalm 111 
This page is intentionally left blank 


\section{CONTENTS}

Page

Acknowledgements $\quad$ xi

Preface $\quad$ xiii

Contributors $\quad$ xv

Chapter 1

The curved, flexible spine and the functions of ligaments and muscles

R.M. Aspden

Chapter 2

Forces acting on the lumbar spine

P. Dolan and M.A. Adams

Chapter 3

What is lumbar instability?

D.W.L. Hukins

Chapter 4

Towards a logical basis for the design of spinal implants

J. Dove

Chapter 5

Biomechanics of the intervertebral disc - disc pressure measurements and significance

D.S. McNally

Chapter 6

The extracellular matrix of the intervertebral disc:

proteoglycan biochemistry

B. Johnstone and M.T. Bayliss

Chapter 7

The effect of mechanical stress on cellular activity in the intervertebral disc

J.P.G. Urban and K. Puustjarvi

Chapter 8

The microanatomy of intervertebral tissues

in the normal and scoliotic spine

S. Roberts 
Chapter 9

Neuropeptides in the lumbar spine

I.K. Ashton and S.M. Eisenstein

Chapter 10

Growth and development of the lumbar vertebral canal

R.W. Porter

Chapter 11

Pathological changes contributing to back pain and sciatica

J.A.N. Shepperd

Chapter 12

Measurement of vertebral blood flow and its

significance in disc disease

A.M.C. Thomas, G.F. Keenan and M. Brown

Chapter 13

The pathophysiology of neurogenic claudication

R.W. Porter

Chapter 14

The role of vascular damage in the development of nerve root problems

M.I.V. Jayson and A.J. Freemont

Chapter 15

The assessment of the patient with low back pain

C.D. Greenough

Chapter 16

Fear-avoidance: the natural history of back pain and its management

J.D.G. Troup and P.D. Slade

Chapter 17

Chemonucleolysis

M. Sullivan

Chapter 18

Experience with chemonucleolysis

D. Wardlaw 
Chapter 19

Lumbo-sacral and spondylo-pelvic arthrodesis

A.D.H. Gardner

Chapter 20

Radical resection of vertebral body tumours:

a surgical technique used in ten cases

M.W. Fidler

Chapter 21

Costs and effectiveness:

approaches to the management of back pain

J.A.K. Moffett and G. Richardson

Index 
This page is intentionally left blank 


\section{Acknowledgements}

We wish to acknowledge the support of Action Research who enabled the University of Aberdeen to establish the Sir Harry Platt Chair of Orthopaedic Surgery and the academic Department of Orthopaedic Surgery. We are also grateful to the Arthritis and Rheumatism Council, the Wellcome Trust, the Colt Foundation, the Sir Jules Thorn Charitable Trust and the National Back Pain Association who have funded our spine research in the Department. Our thanks must go too to Molly Russell who laboured hard over this book to ensure a uniformity of style and accuracy. The responsibility for any errors of presentation that remain must lie with ourselves. 
This page is intentionally left blank 


\section{Preface}

This anniversary book on 'Back pain' celebrates an important occasion, the quincentenary of Aberdeen University. In 1495 Bishop Elphinstone won the support of King James IV to provide a centre of learning in the North. Besides a University which would produce priests, schoolmasters and lawyers, James, who dabbled in medicine, may well have been Elphinstone's encourager to provide for the teaching of medicine and surgery. Playing to the remoteness of northern Scotland, he suggested that the inhabitants were "rude, ignorant of letters, almost barbarians" and were worthy of Britain's first medical school.

Now the capital oil-city of Europe, Aberdeen boasts of a prosperous economy, and a thriving University. And this year also celebrates another anniversary - the fifth year of the founding of the University Department of Orthopaedics. Our strong interest in disorders of the lumbar spine has prompted us to compile an anniversary book on "Back Pain Disorders", inviting contributions from friends around the UK who have done valuable research in this area. They come from many disciplines, basic scientists, physicians and surgeons, to share the results of their research on the most common of medical disorders. The outcome is deliberately personal and no attempt has been made to reconcile the differing views presented. This is meant to be provocative and reflects both the extent of our ignorance and the amount of active work that is still in progress. In order to be topical this book has been produced to a very tight schedule. Inevitably, therefore, we have overlooked one or two names that ought to be included and some, due to pressure of other commitments, have been unable to prepare something in the time we gave them. To these people we apologise, but maybe this gives us scope for a second edition!

One might ask why has back pain disability increased three fold in the past twenty years, when it has been the subject of so much excellent research? We know so much more about the structure of the spine, its physiology, and pathological change. We understand how discs become degenerate, and the complex changes that take place with neurological compromise. We have improved clinical skills, and better imaging. Our therapy is more refined. Surgical skills have improved, helped by impressive implant technology. Why then is back pain disability getting worse?

It is hardly possible that the environment is to blame. With such interest in ergonomics, the creation of a safe environment, and regulations on safe work handling, backs can not be suffering from greater mechanical stresses. Nor is it likely that in the workplace we now have a cohort of individuals with particularly weak backs. For the cause of increased disability we must focus rather on society and the socio-economic climate. Although the science is undoubtedly improving, chronic disability will flourish in a climate of low self-esteem, and broken relationships. These are beyond our immediate remit, but might be areas of productive research for a millennial volume. However enjoy the science, and muse on the answers to a major health problem. Perhaps we are still "rude, ignorant of letters, and almost barbarians" 
This page is intentionally left blank 


\section{CONTRIBUTORS}

M.A. Adams, PhD

Research Fellow

Comparative Orthopaedic Research Unit

Department of Anatomy

University of Bristol

Southwell Street

Bristol

BS2 8EJ.

I.K. Ashton

The Robert Jones and Agnes Hunt

Orthopaedic and District Hospital NHS

Trust

Oswestry

Shropshire

SY10 7AG

R.M. Aspden, PhD

Medical Research Council Senior Fellow

University of Aberdeen

Department of Orthopaedic Surgery

Polwarth Building

Foresterhill

Aberdeen

AB9 2ZD

M.T. Bayliss, PhD

Senior Researcher

Division of Biochemistry

The Kennedy Institute of Rheumatology

Hammersmith

London W6 7DW

M. Brown, PhD

Research Fellow

Department of Physiology

University of Birmingham

The Medical School

Birmingham

B15 2TJ
P. Dolan, PhD

Research Fellow

Comparative Orthopaedic Research Unit

Department of Anatomy

University of Bristol

Southwell Street

Bristol

BS2 8EJ.

\section{J. Dove, FRCS}

Consultant Orthopaedic Surgeon

Stoke-on-Trent Spinal Service

31 Quarry Avenue

Hartshill

Stoke-on-Trent

ST4 7EW

S.M. Eisenstein, PhD, FRCS(Ed)

Consultant Orthopaedic Surgeon

The Robert Jones and Agnes Hunt Orthopaedic and District Hospital NHS

Trust

Oswestry

Shropshire

SY10 7AG

\section{M.W. Fidler, MS, FRCS}

Consultant Orthopaedic Surgeon

Onze Lieve Vrouwe Gasthuis

Postbus 95500

1090 HM Amsterdam

The Netherlands
A.J. Freemont, MD, MRCPath, FRCP(Ed)
Professor of Osteoarticular Pathology
Department of Rheumatology
University of Manchester
Stopford Building
Oxford Road
Manchester M13 9PT 
A.D.H. Gardner, FRCS

Senior Consultant Orthopaedic Surgeon

Essex Spine Centre,

BUPA Hartswood Hospital,

Brentwood, Essex, UK

\section{Greenough, MD, FRCS}

Consultant Orthopaedic Surgeon

Department of Orthopaedic Surgery

Middlesborough General Hospital

Ayrsome Green Lane

Middlesborough

Cleveland

TS5 5AZ

D.W.L. Hukins, DSc, PhD

MacRobert Professor of Physics

University of Aberdeen

Department of Bio-Medical Physics and Bioengineering

Foresterhill

Aberdeen

AB9 2ZD

\section{M.I.V. Jayson, MD, FRCP}

Professor of Rheumatology

Rheumatic Diseases Centre

Clinical Sciences Building

Hope Hospital

Eccles Old Road

Salford M6 8HD

\section{B. Johnstone, $\mathbf{P h D}$}

Department of Orthopaedics

Case Western Reserve University

Cleveland

Ohio

USA

\section{G.F. Keenan, FRCS}

Career Orthopaedic Registrar

Department of Orthopaedic Surgery

Aberdeeen Royal Hopitals (NHS) Trust

Foresterhill

Aberdeen AB9 2ZD

\section{D.S. McNally, PhD}

Lecturer

Department of Anatomy

University of Bristol

School of Veterinary Science

Southwell Street

Bristol

BS2 8EJ

J.A.K. Moffett, PhD, MCSP

Research Fellow

Centre for Health Economics

University of York

Heslington

York

YO1 5DD

R.W. Porter, MD, FRCS, FRCSE

Sir Harry Platt Professor of Orthopaedic

Surgery

University of Aberdeen

Department of Orthopaedic Surgery

Polwarth Building

Foresterhill

Aberdeen

AB9 2ZD

K. Puustjarvi, PhD, MD

Research Fellow

University of Oxford

University Laboratory of Physiology

Parks Road

Oxford

OX1 3PT

\section{G. Richardson}

Research Fellow

Centre for Health Economics

University of York

Heslington

York

YO1 5DD 


\section{S. Roberts, PhD}

Research Fellow

Centre for Spinal studies -Oswestry

Robert Jones and Agnes Hunt Orthopaedic and District Hospital NHS Trust

Oswestry

Shropshire

SY10 7AG

\section{J.A.N. Shepperd, FRCS}

Consultant Orthopaedic Surgeon

The Directorate of Orthopaedic Surgery and Accident and Emergency Medicine

Conquest Hospital

The Ridge

St. Leonards-on-Sea

East Sussex

TN37 7RD

\section{P.D. Slade, PhD}

Professor

Department of Clinical Psychology

University of Liverpool

P.O. Box 147

Liverpool

L69 3BX

M.F. Sullivan, FRCS

Consultanat Orthopaedic Surgeon

95 Harley Street

London W1N 1DF

\section{A.M.C. Thomas, FRCS}

Consultant Orthopaedic Surgeon

Royal Orthopaedic Hospital Birmingham

The Medical School

Birminham

B15 2TJ

J.D.G. Troup, PhD, DSc(Med), MRCS, LRCP, M(FOM)RCP, FergS

Honorary Senior Research Fellow

Department of Orthopaedic Surgery

University of Aberdeen

Polwarth Building

Foresterhill

Aberdeen

Ab9 2ZD

J.P.G. Urban, PhD

Arthritis and Rheumatism Council Senior

Fellow

University of Oxford

University Laboratory of Physiology

Parks Road

Oxford

OX1 3PT

D. Wardlaw, ChM, FRCSE

Consultant Orthopaedic Surgeon

Department of Orthopaedic Surgery

Aberdeeen Royal Hopitals (NHS) Trust Foresterhill

Aberdeen

AB9 2ZD 